\title{
Social Assistance in relief: a necessary movement
}

Identifying the contradictions inherent to social policies under capitalism becomes highlighted when we strive to unveil the broad field of social assistance policies. The contradictory character indicates the mystification of the weight attributed to social assistance in the current phase of capitalism, which has created a culture that affirms it is possible to respond to the demands of the class that lives by its work with a single social policy, and which above all impedes their protection by basic rights. At the same time, this culture strengthens biases about the necessary role of social assistance in the field of social protection in capitalist society.

By recognizing Brazil's condition as a peripheral country in capitalist development, a situation common to Latin American countries, as indicated by the detailed analysis of Ruy Mauro Marini, América Latina: dependência e integração, Brasil Urgente, 1992, which shows how super-exploitation is an inherent characteristic to the conformation of these societies, it becomes essential that social struggles demand the social right to social assistance - independent of contributions, with universal protection and as a responsibility of the state. The right to live with dignity, with social needs met, will only be possible if extracted from the struggle for access to the parcel of wealth that is socially produced. The concentration of wealth in the hands of the few, a characteristic that is constitutive of capitalist society and exacerbated in Latin America, is a matrix of capitalist society that naturally coexists with the slavery of many and the preservation of interests of the few. Through the struggles of the working classes it is possible to identify the constitution of mechanisms to guarantee social protection, whether they are tied to the exercise of salaried labor, or are instruments to confront the precarious nature of this work. It is on this historic ground of the retraction of rights and of fiscal adjustments that the debate about social assistance gains visibility.

In Brazil, social assistance appeared in the debate leading to the 1988 constitution, which recognized the concept of social welfare to be supported by healthcare and social security policies. The recognition that the "social question" requires providing protections for workers that are based on meeting their social needs, led to the elaboration of specific measures. Thus, in addition to composing the concept of Social Welfare in the Federal Constitution of 1988, in 1993 Brazil's Organic Social Assistance Law was promulgated (LOAS), after a long debate in which conceptions that would limit the policy threatened its ability to serve the interests of the population by recognizing social assistance as a social right. The law, as it could not fail to do, condensed these struggles in its text. For example, its guidelines determine that "social needs would have supremacy over economic profitability," although in article 20 of the law, concerning the Continued Payments Benefit - the only constitutionally guaranteed benefit, which would be equal to the national minimum monthly wage, and aimed at the extremely poor - was based on exclusionary criteria. Since then, the political field of social assistance has achieved conquests and setbacks, which have been revealed in academic debates about its centrality in Brazilian social policy in recent years.

The right to social assistance "for those who need it" has been the impetus for critical reflections about the opportunities created on the shaky ground on which lie the characteristics of Brazilian society and its consistently stubborn conservative attitude towards the needs of the class that lives on labor. The conservative thinking affirms that meritocracy is essential to handle the poor population, which is individually held responsible for the problems caused by capital and which must demonstrate merit to receive attention from a state that is privatized by the interests of capital. This conservative attitude towards social rights and to the possibility of providing universal access to the resources needed to decrease Brazil's and Latin America's perverse social inequality has only reverberated during the current crisis.

In this situation, this issue of the Revista Katálysis is essential as it reaffirms its commitment to the quality of the journal and promotes this important and current theme. As the articles demonstrate, immense 
challenges exist related to the advances and setbacks for social protection. Some of the issues problematized here by various authors include: financing for social assistance policy; the constitution and implementation of the Single Social Assistance System (SUAS) on a municipal level; the processing of access to continued payment benefits and the work conducted by social workers; the subordination of the federal system and the breaking with the logic of democratic participation; and the responsibility on the federal, state and municipal levels to establish foundations for social assistance policy. The articles also analyze social assistance monitoring systems, re-establishing the importance of the debate for the production of knowledge about the ways of life and resources provided to meet the demands of the population that solicits services, highlighted by the analysis of services available for the population living on the streets in Rio de Janeiro State.

The broader Latin American debate appears in a study conducted in Argentina, based on interviews with workers in 2011 about social representations of the urban population and the impacts of an important social program.

As a group, the articles - which have various theoretical foundations - present a map of the debates about social assistance policy that are essential for showing how the ideological field of social policy is permeated by conservative positions, articulated through neoliberal ideology, which attempts to remove this debate from the political field. That is, it attempts to remove the debate from "big politics," as warned by Carlos Nelson Coutinho, Contra a corrente: ensaios sobre a democracia e socialismo, Cortez, 2000, and Otávio Ianni, A Sociedade Global, Civilização Brasileira, 1992, and transform everything into administrative space. The scarcity of resources, the driving force of struggles over social policies, is convoked once again, now with the argument that social protection has paralyzed the São Paulo economy. Social investment is confused with undesired costs and a discourse is produced about the dysfunction of government structures. This discourse refuses to analyze the costs imposed by capital on the lives of the immense population. Poverty and violence are treated with banality. Access to social protection is no longer seen to be a clear social right. Workers and their living conditions are criminalized and workers are blamed for their lack of preparation.

The reality needs to be considered based on foundations that are capable of unmasking the perverse logic of the current capitalist crisis. The need to construct a protective system not based on contributions is increasingly affirmed, so that workers are not submitted to troubling constraints in their daily struggles. In considering the reality of the exploited countries located on the periphery of capitalism and the internal disputes of the populations of these countries to assure social protection, it is important that a false dichotomy not be established between work and social assistance, and that social policy is included as an argument in the anticapitalist struggle. To do so, it is necessary to reiterate that they only way to escape the traps of administrative rationality, so highly valued in current analyses in the field of social policies, is through the democratic participation of all actors who circulate in this field and in particular, the users of the policy.

The articles in this issue provide us a special opportunity to enter the field of social assistance policy and construct a critical debate, which is an essential weapon for those who analyze the potentials of this field, without failing to identify the mystifications created to demobilize the struggle.

Good Reading!

Berenice Rojas Couto, May 2015.

\section{Berenice Rojas Couto}

Professor in the School of Social Service at the Pontifícia Universidade Católica of Rio Grande do Sul (FSS/ PUCRS)

FSS/PUCRS - Departamento de Fundamentos do Serviço Social

Avenida Ipiranga, 6681

Partenon - Caixa-postal: 1429

Porto Alegre - Rio Grande do Sul - Brazil

CEP: 90619-900 